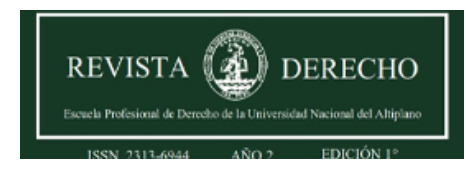

Revista de Derecho

ISSN: 2313-6944

ISSN: 2707-9651

revistaderecho@unap.edu.pe

Universidad Nacional del Altiplano

Perú

\title{
Prevalencia de la Teoría de Unidad de Titulo de Imputación: Determinación de la Naturaleza Jurídica del Extraneus en el delito de Colusión
}

Pérez Livia, Lorenzo; Manzaneda Cabala, Peter Jesús; Aza Suaña, Patty Samanta; Lujano Ortega, Yolanda; Sucari Turpo, Wilson Gregorio; Chura Sotomayor, Wilfredo; Pizarro Flores, Guillermo Alberto Prevalencia de la Teoría de Unidad de Titulo de Imputación: Determinación de la Naturaleza Jurídica del Extraneus en el delito de Colusión

Revista de Derecho, vol. 6, núm. 1, 2021

Universidad Nacional del Altiplano, Perú

Disponible en: https://www.redalyc.org/articulo.oa?id=671870928012

DOI: https://doi.org/10.47712/rd.2021.v6i1.125

\section{(c) (1)}

Esta obra está bajo una Licencia Creative Commons Atribución 4.0 Internacional. 


\section{Prevalencia de la Teoría de Unidad de Titulo de Imputación: Determinación de la} Naturaleza Jurídica del Extraneus en el delito de Colusión

Prevalence of the Theory of Unity of Title of Imputation: Determination of the Legal Nature of the Extraneus in the Crime of Collusion

Lorenzo Pérez Livia

Universidad Nacional de Cajamarca, Perú

Lopeli2@hotmail.com

iD https://orcid.org/0000-0001-7711-7459

Peter Jesús Manzaneda Cabala

Universidad Nacional del Altiplano, Perú

iD https://orcid.org/0000-0002-2596-7205

Patty Samanta Aza Suaña

Universidad Nacional del Altiplano, Perú

iD https://orcid.org/0000-0001-6083-0397

Yolanda Lujano Ortega

Universidad Nacional del Altiplano, Perú

iD https://orcid.org/0000-0001-7178-3346

Wilson Gregorio Sucari Turpo

Universidad de Navarra, Perú

iD https://orcid.org/0000-0001-5874-0966

Wilfredo Chura Sotomayor

Universidad Nacional del Altiplano, Perú

(iD) https://orcid.org/0000-0001-8039-9282

Guillermo Alberto Pizarro Flores

Universidad Nacional del Altiplano, Perú

(iD) https://orcid.org/0000-0002-0849-7299
DOI: https://doi.org/10.47712/rd.2021.v6i1.125

Redalyc: https://www.redalyc.org/articulo.oa? $\mathrm{id}=671870928012$
Recepción: 02 Mayo 2021

Aprobación: 03 Mayo 2021

Publicación: 04 Mayo 2021

\section{Resumen:}

Este tema tiene importancia didáctica para el estudio del Derecho Penal específicamente en el delito de Colusión, coadyuvando la formación de interpretación correcta de la norma de indicada disciplina, sirve de apoyo en el desempeño del trabajo práctico de operadores del Derecho. No obstante, esa relevancia, resulta poco significativa por los escasos trabajos científicos que hayan abordado esta cuestión. Dentro de esas delimitaciones, el presente busco establecer Fundamentos Jurídicos que sustentan la Prevalencia de la Teoría de la Unidad del Título de Imputación en la determinación de la naturaleza jurídica del extraneus en el

NotAS DE AUTOR

Lopeli2@hotmail.com 
delito de Colusión. Desde un modelo descriptivo, de análisis de conversación y de revisión doctrinaria, los principales resultados demuestran que el juzgamiento del extraneus bajo la Teoría de la Unidad del Título de Imputación en el delito de Colusión, garantiza el cumplimiento del fin público del proceso penal de manera íntegra, por cuanto determina la misma responsabilidad penal al intraneus y al extraneus; además permite reprimir la conducta bajo el enfoque de la teoría de la prevención general, así como garantiza la reparación del erario afectado al Estado.

Palabras Clave: Colusión, extraneus, fundamentos jurídicos, intraneus, naturaleza jurídica.

\section{Abstract:}

This topic has didactic importance for the study of Criminal Law specifically in the crime of Collusion, contributing to the formation of correct interpretation of the norm of indicated discipline, it serves as support in the performance of the practical work of Law operators. However, this relevance is not very significant due to the few scientific works that have addressed this issue. Within these limits, this document seeks to establish Legal Foundations that support the Prevalence of the Theory of the Unit of the Imputation Title in the determination of the legal nature of the extraneus in the crime of Collusion. From a descriptive model, conversation analysis and doctrinal review, the main results show that the prosecution of the extraneus under the Theory of the Unit of the Imputation Title in the crime of Collusion, guarantees the fulfillment of the public purpose of the criminal process in a manner full, inasmuch as it determines the same criminal responsibility to the intraneus and the extraneus; it also allows to repress the behavior under the approach of the theory of general prevention, as well as guarantees the reparation of the affected treasury to the State.

KEYWORDS: Collusion, extraneus, legal grounds, intraneus, legal nature.

\section{INTRODUCCIÓN}

La teoría de la unidad del título de imputación contiene un enfoque distinto a la teoría de la ruptura del título de imputación. Para aquella teoría, si bien el extraneus no puede ser autor de un delito especial, si puede ser partícipe del mismo, el cual es correcto, atendiendo a la infracción de los deberes fundamentales y dándole utilidad a la teoría de la unidad de título de imputación, la cual permite ampliar las posibilidades de establecer una responsabilidad jurídica para el extraneus — según la intervención que haya tenido en el hecho ilícito -, para la generalidad de casos de autoría y participación en los delitos especiales, por ser elementos más específicos, tratándose de la intervención de un extraneus(Ramírez, 2019).

Los autores en esta línea argumentan que "la teoría de la incomunicabilidad de las circunstancias (Art, 26 del C.P. peruano), lejos de impedir que el extraneus sea considerado como partícipe del delito especial, la fundamentan" (Punido \& Valdez, 2010, p. 139-140).

Roxin (2014), refiere que para determinar la autoría es necesario, no solo estudiar la teoría del dominio del hecho - al que define como el dominio de la acción final que dará el resultado típico-, sino también, analizar los delitos de infracción de deber, ya que, después de todo, el intraneus es quien ha obtenido una obligación moral o institucional y, por ende, el extraneus no puede considerarse como autor o coautor, toda vez que en estricto sentido y tomando en cuenta la teoría del dominio del hecho, él es quien domina la acción final y sería suficiente para ser autor; sin embargo, no ostenta esa obligación de custodiar un deber.

Los delitos especiales, propios e impropios, solamente el intraneus (el funcionario público, en el caso analizado) podría ser autor del delito, pero los extranei (particulares u otros funcionarios sin la función específica exigida por el tipo, si fuera el caso) serían partícipes del mismo delito incluso cuando fácticamente hayan tenido el dominio del hecho (Mayta, 2019).

Según esta teoría respecto al extraneus, su intervención es calificada a título de partícipe, teniendo en cuenta los principios que rigen la teoría de la autoría y participación, que indican que es el autor quien tiene el dominio de la acción típica, en tanto que el partícipe solo realiza actos de colaboración, no existiendo obstáculo para que los extraneus respondan a título de partícipes de una infracción especial cuando hayan aportado en su realización (Espinoza, 2020).

Los defensores más representativos de esta teoría, Welzel (1964), introduce al ámbito de la de la autoría y participación una síntesis de las teorías objetivo formales, objetivo materiales, y finalmente subjetivas; se 
pronunciaron a favor de la autoría del sujeto cualificado; Maurach (1962), con extensas y elaboradas notas, en los que dio a conocer y llevó a cabo un detenido análisis crítico del finalismo en la versión de Maurach; de igual forma Gallas (2018), intentó fundamentar la autoría del sujeto cualificado con un criterio muy particular, el del dominio psicológico y normativo del hecho; traducidas en una versión incipiente de la noción de dominio del hecho señalando "si el sujeto de detrás deniega su participación, el delito no llega a realizarse y, así, depende de él en su existencia" (Roxin, 1998, p. 280).

En el mismo sentido, Jakobs quien este aspecto lo grafica con el siguiente ejemplo: "El autor que da a un tercero un consejo exitoso de cómo esta tercera persona puede sustraer el patrimonio que aquél tutela, es autor de administración desleal, aun cuando, en el momento de la sustracción, a él le faltara el dominio del hecho" (Jakobs, 1991, p. 57).

En la actualidad las normas de ejecución penal limitan a los juzgadores a sentenciar o absolver al extraneus por el delito contra la Administración Pública en su modalidad de Colusión, generando con ello a tomar decisiones que contradicen el principio constitucional que prescribe toda persona tiene derecho: A la libertad y a la seguridad personales. En consecuencia: Nadie será procesado ni condenado por acto u omisión que al tiempo de cometerse no esté previamente calificado en la ley, de manera expresa e inequívoca, como infracción punible; ni sancionado con pena no prevista en la ley (Constitución Política del Perú, Art. 2, núm. 24, lit. d, 1993).

Es importante porque se encamina a establecer los fundamentos jurídicos para la prevalencia de la Teoría de la Unidad del Título de Imputación en la determinación de la naturaleza jurídica del extraneus en el delito de Colusión.

Se justifica por cuanto, estos fundamentos jurídicos nos ayudan a entender las precisiones de la prevalencia de la Teoría de la Unidad del Título de Imputación cuando se determine la naturaleza jurídica del intraneus y extraneus en el delito de Colusión, para no vulnerar los derechos fundamentales a la libertad y seguridad personal.

Es necesario comprender la conducta descrita por la disposición normativa que se genere "una lesión o puesta en peligro de un bien jurídico, pero sólo como elemento parcial de la acción personalmente antijurídica, nunca en el sentido de que la lesión del bien jurídico agote lo injusto del hecho" (Huerta, 1984, p. 26); y, la infracción que incurre el funcionario público y el extraneus cuando se coluden para causar un perjuicio económico al Estado y no les cree impunidad.

Debido a esta problemática en el presente estudio jurídico se formuló la siguiente pregunta ¿Cuáles son los fundamentos jurídicos para la prevalencia de la Teoría de la Unidad del Título de Imputación en la determinación de la naturaleza jurídica del extraneus en el delito de Colusión?

Por ello, se perfecciona dar la razón que los fundamentos jurídicos para la prevalencia de la Teoría de la Unidad del Título de Imputación para determinar la naturaleza jurídica del extraneus en el delito de Colusión, son: el logro del fin público del Proceso Penal de manera íntegra (Roxin, 2000); la calificación dual del extraneus en su participación jurídica (Sánchez Vera Gómez, \& Trelles, 2002); la maximización de la sanción penal en relación al delito especial (Roxin, 1998); la garantía de la tutela de la seguridad jurídica del colectivo en general (Rincón, 2011) y la optimización del principio Pro Societatis (Gaceta Constitucional \& Procesal Constitucional, 2018, p. 83 - 93).

Puntualizándose, se utilizó la metodología de la investigación aplicando los métodos genéricos (inductivo, deductivo) y los propios del derecho (hermenéutico jurídico, dogmático jurídico, sistemático y argumentación); por cuanto, el propósito de esta investigación fue establecer los fundamentos jurídicos para la prevalencia de la Teoría de la Unidad del Título de Imputación en la determinación de la naturaleza jurídica del extraneus en el delito de Colusión. 


\section{MATERIALES Y MÉTODOS}

El estudio se ha hecho con la realidad social actual que se vive a nivel local, nacional e internacional, cuando se investiga al sujeto activo (extraneus) y al sujeto pasivo (intraneus); a través de la observación y en conversatorios empíricos en forma directa con especialistas en la cuestión. El diseño de la investigación corresponde a una investigación de carácter doctrinaria, de acuerdo al fin que persigue básica y de acuerdo al diseño de investigación descriptivo (Gómez, 2003), explicativo y propositivo. El criterio que se tomó fue la observación de la realidad social que se vive día a día por parte de los órganos jurisdiccionales.

Los materiales utilizados en el tema de investigación fueron bibliográficos por cuanto se accede a la información teórica y doctrinaria respecto a la Teoría de la Unidad del Título de Imputación; así como de las fuentes directas que permiten analizar información respecto de la directriz constitucional del artículo 44. También se accedió a investigación registrada en otros trabajos de investigación, los mismos que sirven para contrastar la hipótesis.

Entre los métodos utilizados en el presente trabajo destacaron los métodos genéricos: inductivo y deductivo. Como métodos propios del derecho fueron manipulados el método hermenéutico jurídico, con los que compruebo el procedimiento que utilizan los operadores de justicia cuando determinan la naturaleza jurídica del extraneus en la infracción del delito de Colusión, por ser la esencia interpretativa. Asimismo, se utilizó el método dogmático jurídico, por cuanto se comprendido lo doctrinario estudiado por connotados e ilustrados juristas nacionales y extranjeros de las instituciones jurídicas. También se utilizó, el método sistemático, para la interpretación de las normas jurídicas relacionadas a la determinación de la naturaleza jurídica del extraneus en la infracción de Colusión. Y, el método de la argumentación, que justifico la pregunta de investigación, la hipótesis de trabajo y el procedimiento a seguir o que se ha seguido para poner a prueba la hipótesis.

La información referente a la prevalencia de la Teoría de la Unidad del Título de Imputación en la determinación de la naturaleza jurídica del extraneus en el delito de Colusión, se han obtenido de la realidad social y de especialistas en la cuestión empíricamente, para ello se recurrió a las técnicas de observación, análisis-síntesis y fichaje o recopilación documental. Como instrumentos se utilizó el registro descriptivo para captar los elementos más importantes con mayor detalle de la Teoría de Unidad del Título de Imputación y la ficha de contenido para resumir la información existente en diferentes fuentes sobre un objeto al que se van aplicar los métodos que sirvieron en la presente investigación, para elaborar la bibliografía final y citas correspondientes.

\section{RESULTADOS Y DISCUSIÓN}

\section{Contrastación de la hipótesis}

La presente investigación corresponde a una de carácter doctrinaria realizándose la eficacia de la hipótesis, mediante los métodos jurídico, dogmático, sistemático y argumentativo; que permitieron la observación de las normas dentro de un contexto determinado, así como del análisis de las normas en su naturaleza. De tal forma, que, mediante el argumento jurídico, se justifica las categorías consideradas en la hipótesis.

La hipótesis para el trabajo de investigación fue: "Los fundamentos jurídicos para la prevalencia de la Teoría de la Unidad del Título de Imputación en la determinación de la naturaleza jurídica del extraneus en el delito de Colusión, son: El logro del fin público del Proceso Penal de manera íntegra; la calificación dual del extraneus en su participación jurídica; maximización de la sanción penal en relación al delito especial; la garantía de la tutela de la seguridad jurídica del colectivo en general, y la optimización del principio Pro Societatis. 
A continuación, el tratamiento de las categorías de la hipótesis.

\section{Logro del fin público del Proceso penal de manera integra}

En un cambio Legislativo de Derecho el Estado regula las directivas de unas personas con otras desde la visión el amparo de los patrimonios jurídicos, así como de la Administración Pública, mediante la elección democrática, por concurso público o designación por las entidades el Estado, ocupan un cargo dentro de la carrera pública tiene la obligación de cuidar el buen ejercicio de la Administración Pública.

Esta perspectiva, en un periodo Constitucional de Derecho, en la cuestión de afectar un bien jurídico vinculado al erario del Estado, según prescribe el artículo 384 del Código Penal, la autoridad que posee la obligación de custodiar por la buena actividad de la Administración Pública, concerta con otro sujeto para defraudar al erario del Estado; donde el funcionario y el extraneus conciertan de manera clandestina causar un perjuicio económico al Estad; es señalar, que el fin del proceso penal, es determinar la responsabilidad de quienes delinquen, en el ilícito penal de Colusión, tanto el funcionario como el extraneus, afectan por igual al Estado en el aspecto erario; ambos deben de asumir en igualdad de responsabilidad penal, bajo los fundamentos jurídicos que sustentan la prevalencia de la Unidad del Título de Imputación.

Es importante que en un Estado Constitucional de Derecho, la normatividad punitiva para la infracción de Colusión, debe tenerse en cuenta "la fuerza vinculante de la Constitución donde son desarrolladas, consignan normas axiológicas, normas dogmáticas o programáticas y normas orgánicas” (Guastini, 2001, p. 157), la Constitución como garantía de la sistematicidad de la regulación de un país, no solo debe ser garantía para la población, sino también para resguardar los erarios dado que tanto el funcionario público como el extraneus son beneficiados por el fraude que ambos acuerdan realizar de manera clandestina; la normatividad no debe proteger a uno (extraneus) más que al otro (funcionario público), por razón que uno tiene el dominio, sino que bajo el enfoque de la Unidad del Título de Imputación y de la fuerza vinculante de la naturaleza, ambos sean protegidos y sentenciados en iguales condiciones, porque la defraudación que realizan los erarios del Estado corresponde a ambos, con una situación en abstracto que el extraneus puede verse beneficiado en iguales o mayores condiciones que el funcionario público.

En la Carta Magna del Estado peruano, prescribe son deberes primordiales del Estado: defender la soberanía nacional; garantizar la plena vigencia de los derechos humanos; proteger a la población de las amenazas contra su seguridad; y promover el bienestar general que se fundamenta en la justicia y en el desarrollo integral y equilibrado de la Nación. Asimismo, es deber del Estado establecer y ejecutar la política de fronteras y promover la integración, particularmente latinoamericana, así como el desarrollo y la cohesión de las zonas fronterizas, en concordancia con la política exterior (Constitución Política del Perú, art. 44, 1993); es decir, no solo debe garantizar la seguridad de la población de las personas de amenazas que provienen del conflicto con otros Estados, sino que debe de proteger a la colectividad de amenazas no tradicionales por la seguridad, parafraseando a Rodríguez Manzano (2004, p. 131) implica el crimen organizado, la delincuencia urbana, los delitos especiales, entre otros.

El Estado dentro de su marco normativo constitucional, debe proteger al colectivo en general de los peligros internos que pueden surgir de la dinámica social; sin embargo, en un marco de desarrollo de la política criminal, el Estado debe conocer, que los riesgos que produce la infracción en sus diversas formas, así como del crimen organizado y de los delitos especiales, es porque influye directamente en la economía del Estado, toda vez que los recursos que son útiles para el bienestar de la población, son destinados para enriquecimiento del delincuencia; el Estado dentro de los fines del proceso penal, le corresponde la persecución de estos ilícitos penales, de tal forma que se pueda aplacar con la atención de los diferentes mecanismos de prevención y sanción penal.

De manera específica, el Estado debe de proteger a la población de situaciones de delincuencia y de los delitos especiales, porque la seguridad no solo significa estar protegidos de los peligros de armas, sino también 
la seguridad del colectivo en general que tienen una correspondencia con los recursos que se asignan para la ejecución de obras, la superación de problemas sociales como la pobreza, la vía a servicios, entre otros, donde el Estado invierte y asigna recursos, siendo que al llegar en su etapa de realización o distribución, son desviados a interés de terceros y de la autoridad que tiene el deber de protección de los recursos, ello ocurre en la infracción de Colusión.

Si la capacidad del Estado es salvaguardar a la población de la delincuencia en sus disparejas formas, en los delitos contra la Administración Pública, se da porque estos tienen relación con la afectación de los erarios destinados para una definitiva región o comuna del Estado, los mismos que permitirían no ser desviados a interés de la autoridad y los extraneus, a brindar servicios, bienestar o ejecutar obras en beneficio de la población; es importante que dentro de los conclusiones del proceso penal, esté la materialización de las sanciones a quienes son responsables de desviar los recursos del Estado de manera delictuosa, dado que ambos han participado en el desvío de recursos estatales, sin tener la regularidad de quiénes de los dos son más beneficiados; en la infracción de Colusión, se considera que el funcionario tiene el dominio del hecho, siendo los dos (autoridad y extraneus), que perjudican los fondos económicos del Estado.

Además, en el caso de la infracción de Colusión, como indica el artículo 384 del Código Penal peruano, para su ejecución es necesario la coexistencia de dos sujetos, un pasivo representado por el funcionario y/ o servidor público y un sujeto activo representado por el particular, quienes se coluden en cualquier acto público, para causar un perjuicio económico al Estado representado por cualquier institución pública.

El Proceso penal, tiene como finalidad la averiguación de la verdad, en la infracción de Colusión es preciso que, el proceso penal dirigido desde la investigación preliminar, hasta la actuación del juicio oral, y emisión de la sentencia, se tenga en cuenta que las actuaciones deben estar dirigidas a conocerse la verdad, por cuanto la infracción de Colusión implica el perjuicio económico del Estado mediante la concertación clandestina de un funcionario público con un particular para defraudar patrimonialmente al Estado; siendo el beneficio ilegal que reciba el funcionario público o el tercero (extraneus) puede ser tan beneficiosa para ambos, porque en ello se basa la concertación ilegal (Ustarroz, 2018).

Además, es preciso mencionar que es exigencia normativa, como fin del proceso penal "la búsqueda de la verdad para condenar culpables y absolver inocentes" (Zamora \& Acevedo, 2014, p. 168); desde un análisis amplio, considerando la infracción de Colusión, que participan dos sujetos para concretarse el delito, así como de quien es el agraviado.

A esto se suma, que el perjuicio de la infracción de Colusión afecta los erarios del Estado, por ende perjudica a una población o comunidad, porque los recursos de los cuales el sujeto activo y pasivo acuerdan beneficiarse, en su conducto regular debieron beneficiar a la satisfacción de las necesidades para los cuales fueron destinadas; debiéndose tener en cuenta que en el caso de la infracción de Colusión, también el extraneus debe responder por la infracción especial, porque tanto el extraneus y el funcionario han perjudicado al Estado en su erario, que estaba propuesto para la ejecución de obras o atención de otras necesidades que beneficiarían a la población.

A esto se suma que, para lograr el fin del proceso penal, es necesario que el extraneus como el funcionario público ambos respondan como autores por la infracción de Colusión, de lo inverso "en no considerar la Teoría de la Unidad del Título de Imputación, la conducta para el extraneus puede quedar complementa impune" (Meini, 2012, p. 4); tiene entre otras finalidades, determinar los culpables y la reparación de los daños causados por quienes cometen el delito (funcionario y extraneus).

Este encuentra sustento jurídico, no de manera explícita para la infracción de Colusión, pero sí de manera implícita, cuando el artículo 25 del Código Penal prescribe: "El que, dolosamente, preste auxilio para la realización del hecho punible, sin el cual no se hubiere perpetrado, será reprimido con la pena prevista para el autor": si bien es cierto, por la infracción de Colusión, el funcionario público tiene condiciones de poder de decisión diferente al extraneus, la consumación del ilícito penal es por la actuación de los dos; por lo que, bajo el enfoque de la Teoría de la Unidad del Título de Imputación, se programa para el logro de los fines 
del proceso penal, que implica "determinar los culpables (finalidad represiva) y perseguir restaurar la lesión ocasionada por el delito (finalidad restaurativa)" (Oré, 2019, p. 4).

Es decir, al no procesar al extraneus con la Teoría de la Unidad del Título de Imputación y no aplicar la represión como lo realiza el autor (funcionario público), provoca que la reparación del bien jurídico perjudicado no se realice en la dimensión íntegra como indican las normas vigentes; ello responde a un proceso lógico, en abstracto en la misión por la infracción de Colusión, el funcionario y el extraneus acuerdan clandestinamente defraudar al Estado por una suma " $X$ " de dinero, luego del cual convienen que el 50\% de $\mathrm{X}$ es para el funcionario y el $50 \%$ de $\mathrm{X}$ para el extraneus, una vez sentenciados si no se hace bajo aludida Teoría especial, por la condición de funcionario y extraneus, la reparación civil y la restauración del erario no será equivalente para ambos, dándose el caso que, el funcionario público por haber sido sentenciado como autor, no tenga la capacidad de responder para la restauración que la resolución mencione. Ello evidencia, la distorsión del fin del proceso penal.

La finalidad del proceso penal, radica en el amparo de la ciudadanía frente a conductas que afectan al común del control estatal de sus propias estructuras y gobernantes en unión con los intereses económicos (...), (Asencio, 2019, p. 119); el proceso penal por la infracción de Colusión, es preciso, considerando la naturaleza del ilícito penal de las circunstancias y modalidad que se ejecuta, tanto el sujeto activo como el pasivo, concurren la forma de afectar al Estado; ambos deben ser juzgados bajo la unidad de imputación, por cuanto no se ha demostrado en lo fáctico cuánto o cómo fue el reparto beneficiado.

También es importante considerar que, por la infracción de Colusión, es necesario saber que la conducta del funcionario público como un delito especial, sino que es importante saber cómo en cualquier delito que, "el supuesto de hecho abarca también todas las circunstancias (...); es decir, la conducta realmente realizada, pero con sus resultados y circunstancias" (Zaffaroni, 2008, pág. 343); en la cuestión por la infracción de Colusión, los resultados y las circunstancias conllevan a contextualizar que tanto el sujeto activo y pasivo, tienen como propósito generar condiciones para “... defraudar a la institución pública...”, como indica el artículo 384 del Código Penal peruano, es preciso que, considerando entre los fines del proceso penal, y del perjuicio provocado al Estado y la comunidad en general, es necesario que quienes han participado en las conductas delictivas de Colusión, deben responder en iguales condiciones en la ejecución del proceso, porque ambos, funcionario y extraneus, han inducido un daño al Estado, donde pueden suceder dos situaciones: En primer lugar, en el juzgamiento prevalece la Teoría de la Unidad del Título de Imputación, permite hacer conocer ante la sociedad, funcionarios y extraneus, los resultados de la comisión por la infracción de Colusión, siendo juzgados en iguales condiciones a ambos, involucra que los dos pueden recibir la misma pena como autores del delito; se promueve "evitar acciones punibles futuras" (Jescheck, \& Weigend, 2014, p. 104), de tal forma que en el aparente hecho de suceder el delito el particular no busque aminorar o no tener responsabilidad en el proceso penal por Colusión. En segundo lugar, la prevalencia en el juzgamiento por la infracción de Colusión prevalece la Unidad del Título de Imputación, permite cumplir con dos principales finalidades del proceso penal (la represión y el resarcimiento); toda vez que, al sentenciar al extraneus considerando en iguales condiciones que el funcionario, admitirá reprimir la conducta para que durante la ejecución de la pena, se someta a la rehabilitación de conformidad el artículo 139 numeral 22 de la Carta Magna del Perú, de tal forma que, tanto el funcionario así como el particular, asuman la culpabilidad penal porque desde la representación de cargos o trabajo que ejecuta cada uno de ellos, la concertación ilegal entre ambos, tuvieron como propósito defraudar al Estado, teniendo el tipo penal indicado en el artículo 384 del Código Penal, entonces con un proceso penal y posterior sentencia del extraneus y del funcionario, permite reprimir la conducta y lograr la reparación del bien jurídico afectado.

En síntesis, el logro del fin público del Proceso Penal de manera íntegra, constituye un fundamento jurídico para la prevalencia de la Teoría de la Unidad del Título de Imputación en la determinación de la naturaleza jurídica del extraneus en el delito de Colusión, porque entre los fines del proceso penal está establecer la responsabilidad penal de quien delinque, de tal forma que, si la conducta delictiva se realiza con 
la participación obligatoria del intraneus y un extraneus, de otra forma no se conforma por la infracción de Colusión, ambos deben responder penalmente con la misma responsabilidad penal, dado que: ambos han provocado el mismo daño al Estado y ambos debieron participar para ello.

\section{Calificación dual del extraneus en su participación jurídica}

En la normativa penal peruana, así como en otras legislaciones penales de otros Estados, de carácter habitual se evidencian, entre otros, dos tipos de delitos: comunes y especiales.

Por los ilícitos comunes, corresponde a la actuación delictiva de cualquier persona; es decir, para la tipificación de la infracción no se requiere de condiciones especiales de quien delinque; empero, en el caso de las infracciones especiales la tipificación implica a algunas personas que tienen alguna condición jurídica (Márquez Cárdenas, \& Gonzáles Payares, 2008, p. 30).

La infracción por Colusión para su tipificación como tal, es necesaria la participación obligatoria de un sujeto activo (intraneus) y un pasivo (extraneus), porque es en base a la concertación de ambos que es posible defraudar erarios del Estado representada por una institución del Estado; evidenciándose en la práctica, que el particular (extraneus) no tiene dominio del hecho, no debe ser juzgado como lo es el sujeto especial (intraneus); sin embargo en un análisis fáctico de la realización de una infracción por Colusión, se concluye que sin la participación del sujeto activo (extraneus) no es posible la realización de la tipicidad delictiva bajo la figura de Colusión.

Por la infracción de Colusión es importante mencionar, sin dejar de lado los argumentos la totalidad de doctrinarios e incluso juristas, "el sujeto pasivo (intraneus) responde como autor y el sujeto activo (extraneus) responde como partícipe, considerando para ello el argumento que el funcionario público debe velar por el buen ejercicio de la correcta Administración Pública, situación que no lo tiene el particular" (Caro John, 2018, p. 1); sin embargo, también es importante mencionar, considerando situaciones fácticas, que sin el sujeto activo (extraneus) es imposible configurar la infracción de Colusión; por lo que, desde la perspectiva de la teoría que sustenta la filosofía de los delitos contra la Administración Pública, quien tiene el deber de velar por el buen funcionamiento de la Administración Pública es el funcionario; dejando fuera del ámbito de decisión al particular (extraneus), con ello solo considerar como partícipe.

En la infracción de Colusión, quien infringe el deber de cuidado es el sujeto pasivo (intraneus); sin embargo, no es un ilícito penal personalísimo, es decir que el beneficio al defraudar al Estado sea específicamente para el funcionario; por ello, teniendo en cuenta la naturaleza de la infracción de Colusión, es cierto que el particular sin tener el deber de cuidar la buena Administración Pública, se convierte en un agente obligatorio para la comisión del ilícito penal; por lo que, se convierte en partícipe y en autor del delito; lo primero porque no se somete al deber de cuidado, y lo segundo porque es necesario para que se concretice el delito; es decir, "que teniendo en cuenta la Teoría de la Unidad del Título de Imputación, el castigo del extraneus debe ser bajo el mismo marco punitivo del autor” (Adrianzen-Román, 2017, p. 49).

En la infracción de Colusión existen dos situaciones puntuales: Primero, la Colusión prescrito en el artículo 384 del Código Penal peruano, es necesario que exista la participación del sujeto activo (extraneus), sin el cual no se puede configurar el delito, es decir que el sujeto pasivo (intraneus) no podría vulnerar el buen funcionamiento del delito, bajo la comisión de Colusión sin la participación del particular (extraneus). Segundo, si para configurarse la infracción de Colusión, es necesaria la participación del particular (extraneus), responde a características equivalentes del autor, toda vez que su participación se hace necesaria en la conducta delictiva.

Por eso, bajo el enfoque de la prevalencia de la Teoría de la Unidad del Título de Imputación en la determinación de la naturaleza jurídica del extraneus en el delito de Colusión, se asegura su participación y su autoría; la primera porque no tiene a su cargo la protección de cuidado del bien jurídico de la Administración Pública, y lo segundo porque sin su actuación no se ejecuta la comisión de la infracción de Colusión. 
Desde la prevalencia de la Teoría de la Unidad del Título de Imputación en la determinación de la naturaleza jurídica del extraneus en el delito de Colusión, también es importante determinar que el partícipe en la realización del hecho es también obra suya, debido a la causa común que él lo realiza con el autor principal.

Si la participación ha de consumarse, tiene además que "afectar a un bien que también este protegido frente al partícipe" (Jakobs, 1997, p. 22).

Por ello, la infracción de Colusión, el funcionario responde indudablemente a la condición de autor porque es el responsable de custodiar por el cuidado de la buena Administración Pública; sin embargo, el extraneus, sin tener poder de decisión ayuda en la ejecución del delito, pero como se hace necesaria su participación para Colusión, recibe doble imputación como partícipe (por extraneus) y como autor por hacerse necesario en la misión del delito.

Desde otra perspectiva, de la infracción de Colusión corresponde a un solo injusto penal, con la participación del sujeto pasivo (intraneus) y del particular (extraneus); por lo que, "cuando varios sujetos toman parte de un ilícito penal no es correcto diferenciar el actuar de cada uno de ellos" (García, 2012, p. 702).

Bajo este argumento, en el caso de la infracción de Colusión, el extraneus participa en la comisión de un ilícito penal, en el que según el Código Penal peruano, para que se configure como tal, es necesaria la asistencia del sujeto activo (extraneus), dado que el sujeto pasivo (intraneus) juntos acuerdan, de manera ilegal y clandestina, defraudar al Estado; por lo que, el fundamento que sustenta la unidad de la imputación en casos de Colusión, es que el sujeto activo (extraneus) es partícipe porque no tiene el deber de cuidar del bien jurídico Administración Pública y es autor porque con su participación se establece el delito; o sea, tiene la doble imputación.

La calificación del extraneus, bajo el razonamiento que su participación es necesaria para la ejecución de la infracción de Colusión, la calificación del mismo debe responder a título de unidad de imputación objetiva, porque tanto el sujeto especial para la elaboración del delito, es necesario la participación del particular (extraneus).

\section{Maximización de la sanción penal en relación al delito especial}

El Estado, entre todas las funciones que de manera explícita e implícita contempladas en el apartado 44 de la Carta Magna del Perú, menciona respecto al amparo de la seguridad de la población como obligación del Estado.

Por ello, en el último párrafo de artículo 41 de la Carta Magna del Perú, indica "El plazo de prescripción se duplica en caso de delitos cometidos contra el erario del Estado".

La razón del último párrafo del artículo 41 de la Constitución Política del Perú, dentro de la política criminal, es extender el tiempo para la persecución de los ilícitos penales, tal como sucede en delitos especiales, para que, por un lado, el Estado tenga mayor tiempo de hacer seguimiento del presunto autor del ilícito penal y por otro lado para evitar que quienes delinquen contra la Administración Pública soliciten la prescripción de sus hechos delictivos.

La Carta Magna del Perú, respecto a quienes delinquen contra el erario, es cierto extiende tiempos para la persecución del ilícito penal contra el erario del Estado, como sucede en delitos especiales, no evidencia de manera explícita la maximización de la pena para quienes participan en la culminación de la infracción penal.

En los delitos especiales contra la Administración Pública, para la consumación respectiva, es ineludible la colaboración de personas especiales (intraneus) y particulares (extraneus) respecto al deber de cuidado, ello se evidencia en la infracción de Colusión, en el mismo que para la ejecución es indispensable la colaboración de un extraneus; desde la perspectiva de la seguridad pública, es importante mencionar que si ambos, intraneus y extraneus, son necesarios para la consumación del delito, bajo el razonamiento de cómo afectan los erarios del Estado, ambos deben de ser sancionados penalmente bajo una misma responsabilidad, es decir bajo la 
Unidad del Título de Imputación; dado que el hecho es el mismo y para la realización del hecho es ineludible la colaboración de ambos (Muñoz Conde \& García, 1993).

La infracción de Colusión, no puede darse en otras circunstancias solo con la participación del intraneus y del extraneus; bajo dicho razonamiento, es necesario que ambos respondan por la misma imputación y en las mismas condiciones de autoría, tanto el intraneus como el particular (extraneus) sean sancionados penalmente como corresponde a la particularidad del autor; se suma, que la sanción penal debe ser asumiendo todas las consecuencias jurídicas, vale decir la pena privativa de libertad, la reposición de los bienes, así como la reparación civil.

La sanción penal y sus resultados jurídicos por la infracción de Colusión, bajo la Unidad del Título de Imputación, deben maximizarse bajo estos razonamientos.

Primero, a decir de Muñoz Conde (1991), si ambos colaboran en la terminación de un mismo hecho que conlleva a un delito; delito de Colusión, ambos deben ser sancionados penalmente con sólidos criterios jurídicos, de manera que ante la sociedad se evidencie la maximización de la pena para el sujeto especial (intraneus) y para el sujeto particular (extraneus), permitiendo ello que ambos sean juzgados por haber concertado defraudar al erario del Estado.

Segundo, las sanciones penales, actualmente establecidas en el apartado 384 el Código Penal, indica que el funcionario o servidor público que comete el delito de Colusión será reprimido con una pena de tres a seis años (Colusión simple) y de seis a quince años (Colusión agravada), dejando libre de dicha punibilidad al extraneus; empero, bajo la Teoría de la Unidad del Título de Imputación, la sanción penal y sus consecuencias jurídicas deben ser igual tanto para el sujeto especial (intraneus) y el particular (extraneus).

Tercero, los bienes o erario donde concerta el intraneus y el extraneus para defraudar, corresponde al erario del Estado y con ello, la designación para la administración de un funcionario público es porque de forma directa o indirecta, beneficiaran a una determinada población, vale decir a un conjunto de personas que son carentes de una necesidad, obra o servicio.

Cuarto, existe la necesidad de una sólida protección de los erarios que administran los servidores o funcionarios públicos, ello no solo aplicando sanciones a quienes tienen la obligación de cuidado y correcta actividad de la Administración Pública, también a quienes con su necesaria participación coadyuvan en la ejecución de la infracción penal.

Por ello, frente a situaciones de infracción de Colusión, es forzosa la preponderancia del castigo penal, porque delinquir contra el erario del Estado, implica afectar la normal administración, así como la afectación de intereses de una colectividad que depende de los recursos que delictuosamente fueron destinados al sujeto especial (intraneus) y al sujeto particular (extraneus).

Incluso, la preponderancia del castigo penal, radica en el hecho, más allá de la cárcel y capacidad que esta tenga para resocializarse, que es la forma más fuerte; sin embargo, la preponderancia de la sanción penal con pena privativa de libertad, no solo debe recaer en el sujeto especial (intraneus), por el ilícito de Colusión para el sujeto particular (extraneus), dado que su participación es ineludible para la clasificación del delito; conllevando a ello, a maximizar las penas para ambos, porque tanto el intraneus como el extraneus atentan contra los recursos del Estado.

La maximización de la sanción penal en concordancia al delito especial de Colusión, sin dejar de lado la directriz constitucional del deber de amparo de la seguridad pública del Estado, reside en la "vigencia de los requerimientos de la igualdad y de la insuficiencia de restablecer la vigencia del ordenamiento jurídico" (Oré, 2019, p. 3); vale decir, en la infracción de Colusión, en el cual el daño está dirigido a los erarios del Estado, el mismo que tiene como destinatario final generar bienestar en la población, es inevitable que se sancione con la maximización de las penas, de tal forma que con ello se controla la continuidad en el ilícito y la prevención de la comisión de la infracción penal, de tal forma que tanto el extraneus, así como el intraneus deben de asumir la misma responsabilidad penal ante el daño que generan al erario del Estado. 
La maximización de la sanción penal en correspondencia a la infracción de Colusión es importante porque corresponde a la prevención general de la ejecución de hechos delictivos posteriores, bajo la norma que ambos (extraneus e intraneus) responden con iguales características penales, vale decir a nivel de autor.

Por ello, maximizar la responsabilidad penal, implica sanciones más severas, de manera específica al extraneus, quien, con la normatividad vigente, bajo el argumento que no dispone de la obligación de cuidado, no posee la misma responsabilidad penal que el sujeto especial (intraneus).

La maximización de la sanción penal en correspondencia al delito especial de Colusión, es necesaria porque genera dos aspectos dentro del tratamiento social de las infracciones penales: porque, genera mecanismos inhibitorios en la colaboración del ilícito penal por parte del sujeto activo (extraneus) y por otra la parquedad de la pena (Luzón, 1997).

Con la normativa vigente, el particular (extraneus) y el sujeto especial (intraneus), tienen sanciones penales diferentes en cuanto a la culpabilidad punitiva que se determina.

Desde el aspecto de prevención, cuando el servidor o funcionario público es sancionado, por el hecho de ser impedido para continuar o acceder a desempeñarse como servidor o funcionario público, más la pena privativa de libertad que le corresponde, se está previniendo para no cometer el propio ilícito penal en situaciones posteriores; sin embargo, en el tema del particular (extraneus), no se consigue prevenir bajo el mismo argumento; por lo que, es importante la maximización de la sanción penal.

\section{Garantía de la tutela de la seguridad jurídica del colectivo en general}

A, entender de Pérez Luño, implica dos exigencias básicas: corrección estructural y corrección funcional (1991). Contextualizando, la postura de Pérez Luño, la conexión a la corrección funcional, implica la garantía de disposición y formulación normal de las normas e instituciones reguladoras de un régimen jurídico, respecto a la infracción de Colusión; porque, las normas deben establecer de manera explícita o implícita, sin duda alguna, que para certificar la seguridad jurídica de la colectividad general, tanto el intraneus y extraneus deben de ser juzgados bajo la Unidad del Título de Imputación; siendo un de ellas garantizar la efectiva de la seguridad jurídica de acorde con el artículo 44 de la Carta Magna del Perú.

La seguridad jurídica desde la representación de corrección funcional trata de afirmar la ejecución del Derecho mediante la sujeción del bloque de legalidad por parte de los poderes públicos y también de los ciudadanos (Pérez Luño, 1991).

Es decir, desde el enfoque de los delitos especiales; y de manera específica en la infracción de Colusión, tanto la autoridad, sea sujeto especial (intraneus), así como el ciudadano (extraneus), por la forma cómo se configura el delito, ambos deben responder bajo las mismas circunstancias, vale decir bajo la representación de la Teoría de la Unidad del Título de Imputación.

En otras palabras, la corrección práctica de la seguridad jurídica vista desde la representación de las sanciones penales en la infracción de Colusión, es importante considerar la conexión con la eficacia del Derecho; vale decir, en qué medida las reglas de amparo de la Administración Pública son efectivas al instante de aplicar sanciones penales.

Por eso, cuando se hace la diferencia entre intraneus y extraneus, en el caso de la infracción de Colusión, a pesar que la ayuda de ambos se hace necesaria, la sanción penal apunta al intraneus bajo el razonamiento que está obligado a tutelar el erario por tener el carácter de especial frente a los demás integrantes del colectivo en general; en la realidad, el artículo 384 del Código Penal peruano menciona que es el funcionario o servidor público quien concierta de manera obligatoria con un tercero (extraneus) para defraudar al Estado; la seguridad jurídica debe garantizar que ambos sean sancionados penalmente y bajo la Unidad del Título de Imputación objetiva.

Como fragmento de la seguridad jurídica, sabiendo lo que persigue la política criminal, es importante que para la infracción de Colusión se aplica la sanción penal sustantivo, no está aplicándose dentro del ámbito que 
involucra la delegación del delito, dado que hace diferencias entre el sujeto especial (intraneus) y el particular (extraneus), a pesar que ambos han sido necesarios para la terminación del delito; es importante que, tanto el sujeto especial (intraneus) y el sujeto particular (extraneus) sean sancionados bajo la propuesta de la Teoría de la Unidad del Título de Imputación, porque es una manera de hacer más efectiva la prevención, con ello mejor amparo de los recursos del erario del Estado, y así promover el cumplimiento de la política criminal.

La política criminal, como perfil de facilitar la seguridad jurídica, es importante tener en cuenta, en los delitos especiales, que "la buena administración contiene dos valores esenciales: control de la discrecionalidad y objetividad así como rectitud en la acción administrativa” (Novoa Curich, 2016, p. 18); en una interpretación extensible de la buena Administración Pública, también corresponde a ella la colaboración de los particulares y diferenciada de administrar o cuidar los erarios del Estado dicha información corresponde a la deducción que la población está con el objetivo de controlar el buen actuar de los sujetos especiales (intraneus); por lo que, si concerta para defraudar al Estado, está contraviniendo su responsabilidad de cuidado, como ciudadano, de la buena Administración Pública, aún más si es que el particular (extraneus) es un sujeto que será responsable de la ejecución de obras o servicios para la colectividad que depende o está relacionada con el sujeto especial (intraneus). Por ello, la sanción penal debe ser en función a la Unidad del Título de Imputación.

Cuando se desarrolla normativa relacionada con derecho penal como fragmento de la seguridad jurídica se exija normas que sean claras y que determinen una real responsabilidad penal de quienes delinquen, cometido el ilícito se sancione bajo el enfoque de prevención, justicia y protección de la seguridad jurídica.

Por eso, en la infracción de Colusión, como está configurado en la actualidad, con una normativa flexible la responsabilidad penal es mayor para el sujeto especial (intraneus), no establece la seguridad dado que, como fragmento de la seguridad jurídica es el amparo de los erarios del Estado y en caso de vulneración o afectación del bien jurídico protegido con la intervención de dos personas (intraneus y extraneus), ambos deben ser sancionados con igual intensidad.

La garantía de la defensa de la seguridad jurídica del colectivo en general es un fundamento que sustenta la prevalencia de la Unidad del Título de Imputación en la determinación de la naturaleza jurídica del extraneus en el delito de Colusión, por tres razones: Primero: "permite dotar de una base empírica a las precauciones de seguridad" (Pérez, 1991, p. 72); vale indicar, que la seguridad jurídica contribuye a la obtención de caudales, en el caso de erarios del Estado, permite satisfacer necesidades para la población; con la infracción de Colusión, se está vulnerando acceso a la satisfacción de necesidades de la población. Segundo: "contribuye a comprobar la eficacia del sistema de seguridad al ponerlo en correspondencia con sus consecuencias en el patrimonio a cuya tutela se dirige" (Pérez, 1991, p. 73); es decir, en el caso de Colusión, la protección del bien jurídico debe responder asegurando la sanción a quienes afectan caudales del Estado, aún más si para la simbolización del delito es necesaria la colaboración del extraneus y del intraneus. Tercero: "legítima la situación de la seguridad en el Estado Social y Democrático de Derecho como cauce operativo indispensable para la obtención de los objetivos constitucionales" (Pérez, 1991, p. 73).

La labor legislativa; respecto a la protección de los erarios del Estado, las normas deben respaldar a una absoluta protección de los bienes jurídicos, dado que el entorno de los erarios, tienen como destinatario final el beneficio a la población.

\section{La optimización del principio Pro Societatis}

En las sociedades actuales, sobre todo los Estados democráticos, las reglas que regulan la defensa de los erarios del Estado, tienen como finalidades la protección del individuo frente a los demás y la protección del colectivo en general frente al actuar delictivo de uno o más individuos que pueden atentar contra un bien jurídico del que en forma directa o indirecta dependen un colectivo de personas (Matus, 2008). 
Los delitos especiales, en forma general, sin descartar otros delitos, implica una afectación de una comunidad nacional, en la infracción de Colusión; la afectación corresponde a recursos destinados a la ejecución de una obra o para bridar servicios; ante la misión de la infracción de Colusión, se debe priorizar el bienestar de la colectividad en general, antes que el sujeto especial (intraneus) y el particular (extraneus), quienes, como cimiento de la política criminal deben de ser condenados teniendo en cuenta la Unidad del Título de Imputación, dado que ambos participan en la misma acción y la actuación de ambos es indispensable para causar un perjuicio económico al Estado.

En la Carta Magna del Perú, en el apartado 149, en una línea interpretativa, permite inferir la forma más segura de velar por el orden social es la prevención del delito (Sánchez Olivencia, 2016); se puede construir dos razonamientos:

En los delitos especiales, se causa un perjuicio económico al Estado, a través de la actuación del sujeto especial (intraneus), en el caso de la comisión de la infracción de Colusión, los afectados son los integrantes de una comunidad o sociedad; por esto, se debe priorizar el principio Pro Societatis.

Bajo la afirmación anterior, en la infracción de Colusión, tanto el intraneus como el extraneus deben ser sancionados teniendo en cuenta la Unidad del Título de Imputación, por estas razones: Primero, porque ambos acuerdan, clandestinamente, defraudar al Estado; Segundo, porque ambos han afectado los erarios del Estado que de forma fehaciente repercute a la colectividad.

Tercero, la infracción penal de Colusión implica la contribución de un servidor o funcionario público y de un sujeto particular (extraneus) que con su participación hace posible la configuración del delito, siendo uno de ellos el mayor beneficiado; actuación que provocan ambos por su participación.

El principio Pro Societatis, contradice el principio Pro Libertates, considerando dentro de él la presunción de inocencia, es cierto también, que ante el ilícito penal de Colusión, no se está valorando la inocencia de quienes han cometido el delito, se está juzgando bajo el cimiento que ambos (intraneus y extraneus), son responsables de un ilícito penal; si la injerencia de ambos es necesaria para comisión del ilícito penal, estos en función de protección del colectivo en general, deben responder bajo la misma responsabilidad penal, lo que se está protegiendo es la colectividad de la afectación en el bienestar de necesidades.

El principio Pro Societatis, implica la defensa de la colectividad ante el amparo de la individualidad, en caso específico de la infracción de Colusión, implica la correcta administración de los causales del Estado, el mismo que beneficiará a una determinada población, ante la aminoración de la responsabilidad penal del extraneus, porque la normatividad actual así permite calificarlo; siendo necesario que en ocupación al perjuicio que puede provocar a la sociedad con la misión del ilícito penal de Colusión, se debe priorizar al colectivo en general ante la diferenciación del sujeto activo (extraneus) y del sujeto especial (intraneus).

En un Estado Social de Derecho, la defensa de los erarios públicos no solo corresponde al amparo de las retribuciones de cada una de las personas, sino también al resguardo del erario que involucra el beneficio de un colectivo de personas.

\section{CONCLUSIONES}

El juzgamiento del extraneus bajo la Teoría de la Unidad del Título de Imputación en el delito de Colusión, garantiza el cumplimiento del fin público del proceso penal de manera íntegra, por cuanto determina la misma responsabilidad penal al intraneus y al extraneus; además permite reprimir la conducta bajo el enfoque de la teoría de la prevención general, así como garantiza la reparación del erario afectado al Estado.

Existe la necesidad de la calificación dual del extraneus en su participación jurídica en el delito de Colusión como autor, bajo el razonamiento que su colaboración es necesaria para la realización del delito especial; por cuanto, el erario afectado al Estado recae en ambos sujetos.

La maximización de la sanción penal en relación al delito especial, ante la concertación para delinquir y defraudar los erarios del Estado, corresponde ser asumida en la misma dimensión para el intraneus y para el 
extraneus; dado que el delito de Colusión afecta el erario del Estado de manera directa o indirecta y también al colectivo en general; por ello, se requiere la preponderancia de la sanción penal bajo la evidencia de que, sí ambos delinquen para beneficiarse; estos asumen la responsabilidad penal bajo el mismo juzgamiento de autoría.

En la Colusión, para fijar la garantía de la tutela de la seguridad jurídica del colectivo en general, es preciso considerar que para la comisión del delito existió la concertación para defraudar al Estado; conllevando ello, a que el sujeto especial (intraneus) contravenga su responsabilidad de garantizar la obligación de cuidado del correcto funcionamiento de la Administración Pública; por cuanto, si el particular (extraneus) es juzgado como autor del delito de Colusión, permite proteger legalmente los erarios del Estado, que tiene como beneficiarios al colectivo en general; garantizando de esta manera la seguridad jurídica.

Teniendo en cuenta la optimización del principio Pro Societatis para la calificación del extraneus en el delito de Colusión, corresponde sancionar penalmente tanto al intraneus como al extraneus, acorde a la Teoría de la Unidad del Título de Imputación; porque ambos acuerdan, clandestinamente defraudar al Estado, además; afectan la correcta Administración Pública, por cuanto de forma directa o indirecta repercute en la colectividad en general; y si ambos son sentenciados como autores del delito, se optimiza de manera eficaz el amparo de la colectividad.

\section{REFERENCIAS}

Adrianzen, P. (2017). La participación en los delitos especiales. Análisis de la intervención de un extraneus en el delito de enriquecimiento ilícito. [Tesis de maestría, Universidad de Piura].

Asencio, J. (2019). La crisis del proceso penal derechos humanos y socialización de la culpa. En G. Priori Posada, Justicia y proceso en el siglo XX. Lima, Perú: Palestra.

Caro, J. (2018). El "extraneus" en delitos cometidos por funcionarios públicos. Lima, Peru: Legis.pe.

Constitución Política del Perú [Const] Art. 2, numeral 24, literal d), 29 de diciembre de 1993.

Constitución Política del Perú [Const] Art. 44, 29 de diciembre de 1993.

Espinoza, A. (2020). La participación del «extraneus» en los delitos del deber. Comentarios al Acuerdo Plenario 3-2016. Lima, Perú: Redacción LP.

Gaceta Constitucional \& Procesal Constitucional, tomo 125, mayo 2018, pág. 83-93.

Gallas, W. (2018). La Teoría del Delito. 1ra. Ed. Buenos Aires, Argentina: B de F.

García, P. (2012). Derecho Penal - parte general. Lima, Perú: Jurista Editores.

Gómez, V. (2003). Los delitos especiales. [Tesis de doctorado, Universidad de Barcelona]. https://www.tesisenred.net /bitstream/handle/10803/1411/TESIA.pdf?sequence $=1$ \&isAllowed $=\mathrm{y}$

Guastini, R. (2001). Estudios de la teoría constitucional. México D.F.: Instituto de Investigaciones Jurídicas.

Huerta, S. (1984). Sobre el contenido de la antijuridicidad. Madrid, España: Tecnos.

Jakobs, G. (1991). Derecho Penal. 2da. Edición. Madrid, España: Marcial Pons.

Jakobs, G. (1997). Derecho Penal. Parte general. Fundamentos y teoría de la imputación. Madrid, España: Marcial Pons. Jeschek, \& Weigend, T. (2014). Lehrbuch. AT.

Luzón, D. (1997). Derecho Penal, Parte General, Tomo I. Fundamentos. La estructura de la teoría del delito. Madrid, España: Civitas.

Maurach, R. (1962). Tratado de Derecho Penal. Trad. En dos tomos. Barcelona, España: Ariel.

Mayta, N. (2019).¿El 'extraneus' instigador requiere alguna cualificación especial? Una tarea pendiente en nuestra Corte Suprema. Lima, Perú: Redacción LP.

Márquez, \& Gonzáles, O. (2008). La coautoria: delitos comunes y especiales. Informes de investigación. Grupo Derecho Penal. 
Matus, J. (2008). La protección de la seguridad personal en el Código Penal. Revista Ius Et Praxis. Año 15.

Meini, I. (2012). Temas de Autoría y Participación en los delitos contra la administración pública. Boletín Anticorrupción del IDEHPUCP $\mathrm{N}^{\circ} 14$.

Muñoz, F. (1999). Teoría General del Delito. 2da Ed. Valencia: España: Temis S.A.

Muñoz, \& García, M. (1993). Derecho Penal. Valencia, España: PG.

Novoa, Y. (2016). El buen gobierno como bien jurídico categorial de los delitos de corrupción. Boletín anticorrupción y justicia penal.

Oré, A. (2019). La finalidad del proceso penal. Lima, Perú: Griley.

Pinedo, C; Valdez, F y Vásquez, E. (3-10 de noviembre de 2010). VII Congreso Nacional de Derecho Penal y Criminología. [Discurso principal] Huacho, Perú: Printed in Perú.

Pérez, A. (1996). Seguridad Juridica. Madrid, España: Trotta.

Ramírez, M.S. (14 de octubre de 2019). La responsabilidad del extraneus en el marco de los delitos especiales. Una visión delprincipio de unidad de título de imputación. Ciencia Jurídica. Departamento de Derecho. División de Derecho, Política y Gobierno, Universidad de Guanajuato. (Año 9, No. 17, 2020).p. 68.

Rincón, J. (2011). De la discrecionalidad, la estabilidad jurídica y la eficiencia en la gestión de los recursos humanos. El caso de las fuerzas militares colombianas. En Seguridad jurídica, estabilidad y equilibrio constitucional. I Congreso del Doctorado en Ciencias Jurídicas. Bogotá, Colombia: Pontificia Universidad Javeriana. https://webcache.googleusercontent.com/search?q=cache:4PSnZI3e_a8J:https://dialnet.unirioja.es $/$ descarga/articulo/4760108.pdf $+\& \mathrm{~cd}=1 \& \mathrm{hl}=\mathrm{es}-419 \& \mathrm{ct}=\mathrm{clnk} \& \mathrm{gl}=\mathrm{pe}$

Rodríguez, I. (2004). El Tratado-marco de seguridad democrática en Centroamérica: ¿un modelo para la seguridad de América Latina? Aproximación a las cuestiones de seguridad en el continente americano. CESEDEN No 73. Santiado de Compostela. https://dialnet.unirioja.es/descarga/libro/562697.pdf.

Roxin, C. (1998). Autoria y dominio del hecho en el derecho penal. Madrid, España: Marcial Pons.

Roxin, C. (1998). Autoría y dominio del hecho en Derecho Penal. $6^{a}$ ed. Madrid, España: Marcial Pons.

Roxin, C. (2000). Derecho Procesal Penal. Buenos Aires, Argentina: Editores del Puerto SRL.

Roxin, C. (2014). Derecho Penal, Parte General. Tomo II, Especiales formas de aparición del delito. España: Thomson Reuters-Civitas.

Sánchez Vera Gómez, \& Trelles, J. (2002). Delito de infracción de deber y participación delictiva. Madrid, España: Marcial Pons.

Sánchez, C. (2016). In dubio pro societate. Opinión.

Ustarroz, J. (2018). Algunas reflexiones sobre el concepto de "verdad" en el proceso penal. https://derechopenalonline.c om/algunas-reflexiones-sobre-el-concepto-de-verdad-en-el-proceso-penal/

Welzel, H. (1964). El nuevo sistema del Derecho Penal. Una introducción a la doctrina de la acción finalista. Barcelona, España: Ariel.

Zaffaroni, E. (2008). Manual de Derecho Penal. Buenos Aires, Argentina: Ediar.

Zamora, M. (2014). La búsqueda de la verdad en el proceso penal. Acta Academica Jurídica. Barcelona, España: Ariel Derecho.

\section{INFORMACIÓN ADICIONAL}

Sobre el artículo: Artículo derivado de la tesis presentada a la Unidad de Posgrado de la Facultad de Derecho y Ciencias Políticas de la Universidad Nacional de Cajamarca (Perú). 